\title{
EL MAÍZ EN ITALIA, SIGLOS XVI-XIX: PRECIOS, MERCADOS Y HACIENDAS AGRÍCOLAS (DOS CASOS DE ESTUDIO: LOMBARDÍA Y UMBRÍA)
}

\author{
Luca Mocarelli y Manuel Vaquero Piñeiro \\ Università Bicocca di Milano \& Università di Perugia
}

\begin{abstract}
RESUMEN. El presente estudio tiene por objetivo presentar algunos aspectos clave que nos ayuden a comprender la introducción y expansión del maíz en Lombardía y Umbría en los siglos XVI y XIX, dos regiones emblemáticas en lo que concierne a su historia en Italia. El trabajo utiliza material de archivo inédito para comprobar la validez de una serie de presupuestos de investigación. En primer lugar, la cronología de la introducción del nuevo cultivo, un proceso histórico que, sin duda, implicó la acuñación de nuevas palabras para designar un alimento desconocido hasta la segunda mitad del siglo XVI. Veremos luego las rutas que siguió la "revolución del maíz" en Italia, atendiendo al papel jugado en este sentido por los grandes propietarios de tierra. Otro tema de interés que trataremos son los cambios que la nueva planta introdujo en la estructura productiva, o la forma en que su consumo modificó el tradicional funcionamiento de los mercados de cereal, tanto urbanos como rurales, al favorecer el desarrollo de las haciendas y la aparición de mercaderes especializados. Desde este punto de vista, un aspecto central de nuestro estudio será la posición del maíz en la formacion de ese mercado de cereales. Por esta razón, la investigacion presenta toda una serie de datos estadísticos que demuestran la validez de la tesis relativa a la integración de los circuitos comerciales y, lo que es más emblemático, la perfecta correlación en ellos de los precios. Al respecto, la evolucion de esos precios, tanto del trigo como del maíz, pondrán de relieve la integración de amplios espacios comerciales en la Italia de los siglos XVIII y XIX.
\end{abstract}

Palabras clave: Italia, Edad Moderna, maíz, mercado, precios, haciendas agrícolas.

Recibido: 10-7-2018·Aceptado: 2-10-2018·luca.mocarelli@unimib.it·manuel.vaqueropineiro@unipg.it 
Abstract. This study aims to present some key aspects to understand the introduction and expansion of corn in Lombardy and Umbria between the sixteenth and nineteenth centuries. Choosing as a case study two emblematic regions concerning the history of corn in Italy throughout the Modern Age, the work uses unpublished archival material to verify the validity of a series of research tracks. First, the chronology of the introduction of a new crop, a historical process that undoubtedly involved the coining of new words (Formentone, Granturco) to designate an unknown food until the second half of the 16th century. We will see the routes followed in Italy by the "corn revolution", calling the cause played by the great land owners. Equally another subject of great interest are the changes that the corn implied in the productive structure, while the consumption of corn modified the urban and rural markets, favoring the development of specialized haciendas and merchants. From this point of view, a central aspect is the position of corn in the formation of the cereal market. Therefore, the research presents a series of statistical data that demonstrate the validity of the thesis on the integration of commercial circuits and what is more emblematic, the perfect correlation of prices. The evolution of prices for both wheat and corn indicate the integration in the eighteenth and nineteenth centuries of large commercial spaces.

Keywords: Italy, Early Modern History, corn, market places, prices, farms.

\section{Introducción}

El maíz, tras un largo proceso de internacionalización, es una de las plantas comestibles que ha impulsado la globalización de la agricultura y de los alimentos básicos. En efecto, después de haber desembarcado en la Península Ibérica a finales del siglo XV, se extendió geográficamente hasta llegar a ser hoy el cereal más cultivado (569 millones de toneladas), por delante del trigo (417 millones de toneladas) y del arroz (345 millones de toneladas) (Demontis, Cadoni, Sassu, 2009, pp. 6-7). Actualmente, y si exceptuamos a unos pocos países, podemos encontrarlo presente en los cinco continentes, aunque las principales potencias productoras sean los Estados Unidos, Brasil, China, la Unión Europea y México. Por tanto, puede afirmarse que, moviéndose de oeste a este, el maíz ha protagonizado una enorme expansión fuera del continente americano, llegando a las costas del Mediterráneo a comienzos de la edad moderna.

Un aspecto que genera no pocas controversias es el nombre que recibió la nueva planta una vez comenzó a difundirse en Europa. En muchos países del continente, como ocurrió en Italia, la llegada del maíz y su introducción en el seno de un sistema agrícola maduro, implicó la necesidad de identificarlo, de atribuirle un nombre que lo distinguiera de los demás cereales (Messedaglia, 1927, 41-58). Si en algunos casos la solución adoptada fue la de permanecer fieles a la palabra original (mahis), en otros, 
se le atribuyó el nombre utilizado para designar a alguno de los cereales menores que ya se cultivaban, sin excluir que recibiese otras denominaciones que tuviesen en cuenta su origen lejano y exótico (Franconie, 1997). En este sentido, el caso italiano es ejemplar, porque a veces prevaleció la norma de dar al maíz una denominación que lo identificase con el trigo, de ahí frumentone o formentone, en otras, se recurrió al nombre de cereales como el de 'trigo sarraceno', 'trigo siciliano', sorgo o espelta, mientras que en otras ocasiones predominó el criterio de indicar la zona, más o menos presunta, de origen de la planta. Fue de esta forma como, y no sólo en Italia (Cazzola, 2014, pp. 311-312), se consolidaría la asociación entre maíz y Turquía, a causa, quizás, de que el llamado 'grano turco' se cultivaba en amplias áreas del imperio turco ya desde los años setenta del siglo XVI (Stoianovic, 1966; Heine, 2017, pp. 149-150). Sobre este último punto, que va más allá de ser una mera anécdota, resulta importante saber que todavía en 1829 Gabriele Calindri, en su volumen sobre la economía de los Estados Pontificios, afirmaba de manera errada que el maíz «llegó a Alemania y a Europa desde la Arabia Felix, adonde lo habían llevado los turcos a comienzos del siglo XVI» (Calindri, 1829, 466). Dejando de lado el posible papel jugado por el área turca como puente en la difusión del maíz, lo cierto es que ante la pluralidad de nombres y de préstamos lingüísticos, especialmente provenientes de cereales ya existentes, su denominación genera una cierta confusión en el terreno de la investigación histórica. Así, por ejemplo, las fuentes contables de las haciendas agrícolas no siempre van a ofrecernos una correcta identificación del cereal que realmente cultivaban y contabilizaban. Éste es un problema que nos acompañará a lo largo de las páginas que siguen.

Si la denominación de zea mays en Italia genera a menudo dudas y nos obliga a movernos con prudencia en las fuentes históricas, la información que poseemos sobre las fases de su expansión geográfica es mucho más segura (Mantelli, 1998). El maíz aparece documentado en Nápoles a comienzos del siglo XVI y poco después lo encontramos en Venecia. De hecho, los libros de botánica editados en la primera mitad del siglo XVI incluyen ya la nueva planta. El naturalista Ulisse Aldrovandi la describe en detalle en 1551 y algunos años más tarde, en 1564, lo hará también Agostino Gallo en su famosa obra, Los diez días de la agricultura y los placeres de la villa (Galli, 2016; Gentilcore, 2017). Tras esta fase inicial, en la que el maíz se aclimató en los jardines privados, donde se reunían las especies vegetales llegadas de lejanas y misteriosas tierras (Ambrosoli, 1992), la planta pasó de su condición de exótica rareza a la de cereal sembrado por razones alimenticias. La cronología y los caminos seguidos por su difusión a lo largo de la Península Italiana han sido reconstruidos por una abundante historiografía (Doria, 2002; Coppola, 1979; Finzi, 2009). Así sabemos que antes de que finalizara el siglo XVI, la planta había protagonizado un lento pero constante avance a lo largo del valle del Po, desde el área veneciana hasta las regiones de Lombardía y 
Piamonte. Luego, entre los siglos XVII y XVIII, llegaría a las regiones centrales de Italia - Toscana, las Marcas, Umbría - donde se consolidó durante el siglo XVIII (Desplanques, 1969). Menos común, por razones climáticas evidentes, es el cultivo del maíz en las áreas del sur del país, si bien tampoco allí faltaron ocasiones propicias para la difusión de un cereal que ofrecía posibilidades de producir para el mercado. De ahí que a comienzos del siglo XIX, los campesinos del Mediodía italiano intentasen consolidar un cultivo que les garantizaba una alta productividad, al tiempo que permitía la comercialización del muchísimo más rentable trigo en los grandes mercados de la región (Cuoco, 2008, p. 408).

Sobre las consecuencias agrícolas y demográficas de la penetración del maíz en Europa tenemos una amplia información. Sabemos por ejemplo que en las áreas del continente caracterizadas por la existencia de unas condiciones ambientales favorables a su cultivo, la planta tuvo mucho éxito, hasta acabar ocupando, como cultivo de primavera, el espacio dedicado a toda una serie de cereales menores, como el mijo, el sorgo o el alforfón, los cuales acabarían desapareciendo de las explotaciones agrícolas, en particular, de las más pequeñas (AA.VV., 1992). Es obvio, que la razón de tal sustitución fue la mayor productividad del maíz, visto que, y resumiendo lo dicho en su día por Franco Cazzola, «las semillas maduraban en la planta sin caer y estaban relativamente protegidas de los agentes atmosféricos y de los ataques de pájaros y roedores» (Cazzola, 2014, p. 310). Se comprende, por tanto, que la harina de maíz, si bien nunca alcanzó la fama y el valor de la del trigo, entrase pronto en los hábitos alimenticios y gastronómicos tanto de las clases populares como de la nobleza italiana. Muestra de ello es el cuadro en el que el pintor veneciano Pietro Longhi, hacia 1740, retrata a un grupo de personas dispuestas a comer una olla de 'polenta'. En este sentido, por los mismos años, entre las familias nobles que pasaban sus días de ocio y descanso en sus respectivas casas de campo, se puso de moda el consumo de la mencionada 'polenta', un plato que hasta entonces era propio de la forma de vida y de la alimentación de los campesinos (Torri, 2017, p. 215).

Ya fuera por necesidad o por simple curiosidad, el maíz conoció una creciente e imparable difusión. Se consolidó en los ciclos económicos de las explotaciones agrícolas y dio lugar una profunda transformación de los paisajes agrícolas, pues supuso el rápido abandono de las rotaciones bienales basadas en la combinación de barbecho y trigo (Sereni, 1997, pp. 178-181). Lo mismo puede decirse en lo que se refiere a la alimentación, ya que, y en un contexto dominado por una dieta pobre y poco diversificada la 'polenta' llegó a representar un alimento seguro y de fácil adquisición. Tanto, que no podemos evitar referirnos a los efectos negativos que sobre la población de muchas regiones italianas originó la pelagra, llamada también el «mal rosa», una enfermedad que era consecuencia directa de una dieta basada en un consumo casi 
exclusivo de maíz (De Bernardi, 1984; 1982). Aunque es cierto que, y a lo largo del siglo XIX, las familias campesinas, pese pagar un duro tributo a la pelagra, gracias a esta planta consiguieron liberarse definitivamente el flagelo del hambre y la carestía (Mocarelli, 2015, pp. 62-63).

Si la difusión y las consecuencias médicas del maíz han sido convenientemente estudiadas, no puede decirse lo mismo de otras cuestiones sobre las que tenemos menor información. Una de ellas, es su contribución a la formación del mercado de cereales durante la edad moderna (Levi, 1991, pp. 155-162). De hecho, el objetivo de este trabajo es precisamente indagar en ello, justo cuando su cultivo se había más o menos popularizado en todas y cada una de las regiones de la península. Para abordar este tema, resulta imprescindible ir más allá del clásico enfoque que entiende la formación de esos mercados únicamente a partir de movimiento de los precios del trigo, el cereal más consumido en el ámbito urbano, ya que esta es una forma de ver el tema que entiende que el maíz es un recurso destinado al mero autoconsumo de los agricultores.

Aunque nuestra investigación sobre la penetración del maíz en los mercados de las ciudades italianas está todavía en sus inicios, presentamos aquí algunos resultados parciales de la misma, referidos a dos realidades muy diferentes, tanto desde un punto de vista geográfico como demográfico y económico, el caso de Lombardía y Umbría, dos regiones emblemáticas en lo relativo a la historia de la planta.

En este trabajo utilizamos material de archivo inédito, a partir del que hemos obtenido una serie de datos estadísticos que nos remiten al funcionamiento de un amplio número de grandes y pequeños mercados urbanos, los cuales nos permitirán averiguar si hubo o no una integración de los circuitos comerciales del cereal y, lo que es más relevante, si se dio o no una sincronía entre los precios de los distintos productos presentes en ellos (Federico, 2007). A este nivel, sabemos que la evolución de los precios, tanto para el trigo como del maíz, denota la existencia de una cierta complementariedad entre ambos productos en amplios espacios comerciales de Italia durante los siglos XVIII y XIX. Ante esta evidencia, lo que pretendemos es establecer que el maíz, además de haber contribuido a ampliar de una manera decisiva la oferta alimentaria de la población urbana y rural, no puede quedarse al margen de los estudios relativos a la determinación de los umbrales de pobreza o de los niveles de vida de las clases populares (Malanima, 1976). Para ello, partimos de la base de que una parte importante del maíz servía para el sustento de las familias campesinas, pero también de que el aumento de las cosechas no se destinaría única y exclusivamente al abastacimiento de los mercados locales, ya que una parte de la producción iría a parar también a los mercados urbanos. De ser esto así, de destinarse una parte de la cosecha al abasto de esos mercados, habría entonces que sopesar el papel que en todo ellos habrían jugado los grandes propietarios de tierras. Más aun, cuando todo apunta 
a que desde el siglo XVIII se produjo el paso de un mercado urbano dominado por el trigo y una serie de cereales secundarios, a otro articulado en torno al trigo y el maíz. En ese paso, lo sucedido al respecto en los pequeños mercados urbanos y rurales tuvo un papel decisivo.

\section{Cronología de la difusión del maíz: Lombardía y Umbría}

Nos detendremos primero en explicar cómo se produjo la penetración progresiva del maíz en la campiña italiana, detallando lo sucedido al respecto en el norte de la península. Conforme a ello, desde la República de Venecia, donde la planta se cultivó desde al menos 1554, se extendió luego por el valle del Po hasta alcanzar Verona en 1611, Brescia en 1630 y, más tarde, Bérgamo en 1632. En paralelo, se aprecia otra vía de difusión, esta vez hacia el este, que le llevó a estar presente en Treviso en 1592, en Belluno en 1617 y en Udine en 1620 (Finzi, 2009, pp. 27-32). En el siglo XVII, y más aún en el XVIII, esta distribución geográfica culminaría con un logro triunfal, como fue el de conseguir multiplicar por tres la producción de maíz obtenida en el Estado de Milán entre 1716 y 1775 (Doria, 2002, p. 571). Si en 1716-1720 la producción de trigo en Lombardía equivalía al 33\% del total de la producción agrícola, en 1774-1778 ese porcentaje había descendido al 24\%, mientras que, y en el mismo período, el maíz pasó del 22 al 42\% del total (Levi, 1991, p. 157). Por encima de estas cifras, que son una muestra de la consolidación de un proceso de llegada y aceptación de la nueva planta, lo que resulta realmente interesante es el hecho de poder asistir a la formación en las tierras del valle del Po de una estructura agraria, en la cual, y bajo la presión de las hambrunas que allí se dieron entre finales del siglo XVI y 1632, se sentaron las condiciones para la introducción del maíz en el ciclo de cultivos de la zona (Alfani, 2010, pp. 116-128). Se diseña así en el tiempo una cronología que vincula el norte de la Península Italiana con otras áreas europeas (Stoianovic, 1966; Rebourg et al., 2002), a la vez que dicho norte va a mostrar una diferencia evidente respecto a lo sucedido en las regiones del centro de Italia, donde durante el siglo XVII el maíz siguió siendo un producto de escaso valor comercial, destinado sobre todo a la alimentación de los animales. Tal y como se desprende del estudio de las contabilidades de las grandes explotaciones agrícolas de la Toscana y las Marcas, habrá que esperar a las últimas décadas del siglo XVII, incluso a primeras décadas del XVIII, hasta encontrar en ellas rastros de la existencia cosechas regulares de maíz (Mineccia, 1983; Moroni, 2016).

Asimismo en el caso de Umbría, una región situada en el centro de Italia, caracterizada por poseer una agricultura en la que predominaba el régimen de la aparcería (Nenci, 1989), la expansión del maíz se registrará en pleno siglo XVIII, como nos lo indican los listados de precios imperantes en los mercados urbanos (Mapa 1). Así, en 
Gubbio el cultivo aparece por primera vez hacia 1727, en Asís en 1741 y en Perugia en 1766 (Pannacci, 1994-95; Aristei, 1996-97). Las noticias que poseemos para los años ochenta del siglo XVIII se refieren al maíz, o formentone, como un cultivo bastante común en los territorios dominados por la mencionda ciudad de Perugia. Por su parte y ya en pleno periodo francés, en el mercado de Orvieto, la presencia de la planta se registra regularmente sólo a partir de 1813 (De Santis, 1994-95).

Llegado este punto, es necesario subrayar la coincidencia cronológica que esa presencia muestra en los mercados de las ciudades entre los Estados Pontificios y Toscana, una región esta última donde el maíz aparece con regularidad desde las últimas décadas del siglo XVIII: tras 1780 en Sarteano, 1793 en Castiglione Fiorentino y 1802 en Cortona (Aggravi, 1999-2000; Polvani, 1999-2000; Cipollini, 2001-2002). Aunque nuestros datos son todavía parciales, nada nos impide sin embargo afirmar que en las regiones del centro de Italia llegó mucho más tarde que al área lombarda, en la cual,

\section{Mapa 1. Localización geográfica de las ciudades de la Toscana y Umbría donde se registra la llegada del maíz en el siglo XVIII}

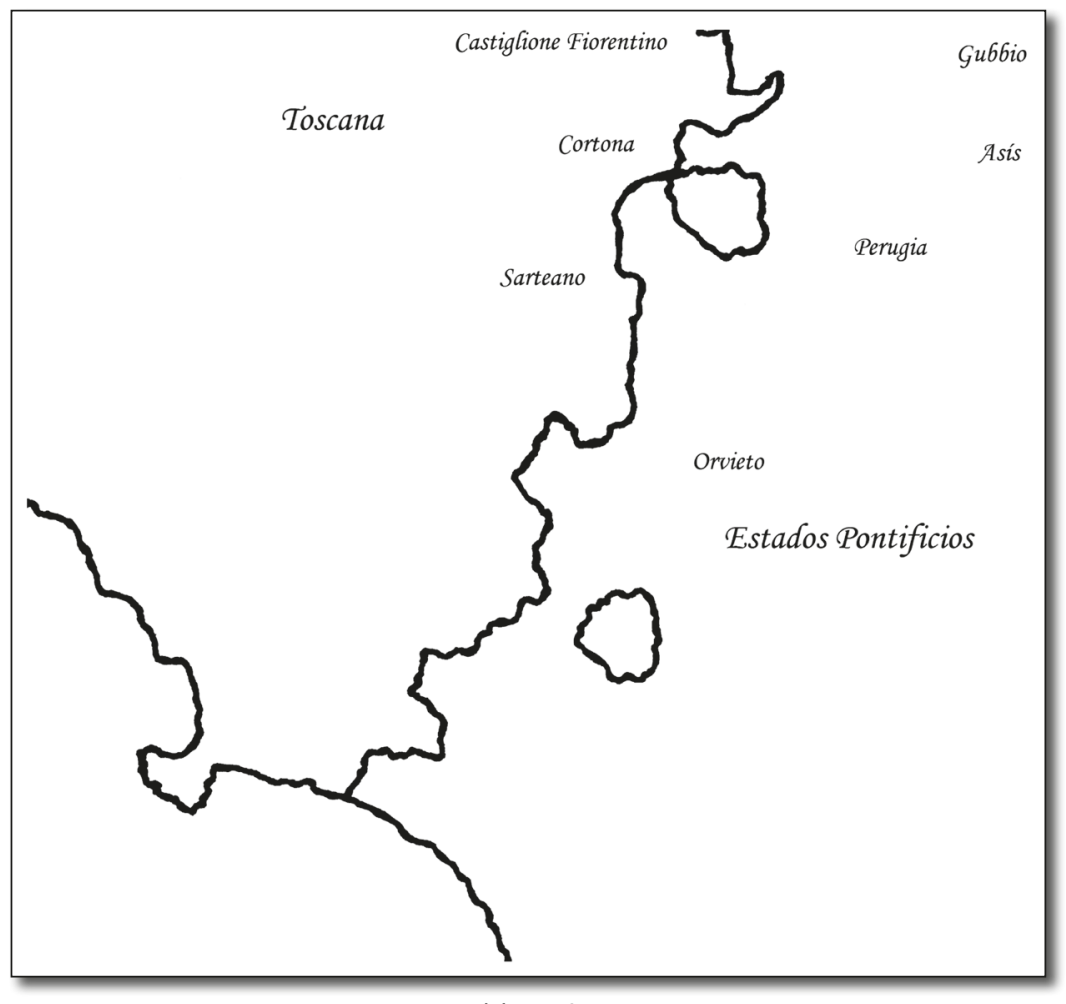

Fuente: Elaboración propia. 
la comercialización del maíz en los mercados urbanos - en Bérgamo, en Brescia o en Desenzano - comenzó mucho antes, en la segunda mitad del siglo XVII. Incluso en un gran centro urbano como Milán, donde la mayoría de la población consumía pan blanco de trigo, el maíz sólo aparecerá en el mercado oficial a partir de 1717.

Ahora bien, una cosa es establecer su aparición en los mercados urbanos y otra, a veces muy distinta, saber cuándo se produjo la introducción de la planta en los sistemas de cultivo de cada región. Algo que podemos llegar a averiguar si centramos nuestra atención en la documentación privada, esto es, en las contabilidades de las granjas y explotaciones agrícolas. Aparece entonces un panorama mucho más complejo, dado que, como sabemos, el maíz no se difundió de un modo uniforme sobre el territorio y menos aun ese proceso presenta una cronología lineal. Lo cierto es que su difusión siguió trayectorias diferentes en el espacio y en el tiempo, las cuales, sin duda, son la lógica consecuencia de las condiciones imperantes en cada una de las zonas en las que había de darse su asentamiento y extensión.

La imagen resultante del manejo de esa documentación privada revela la existencia de una diferencia en los ritmos cronológicos que hemos señalado para las regiones de Lombardía y Umbría. De hecho, en muchas haciendas lombardas la llegada del maíz se documenta en la primera mitad del siglo XVII: en 1620 en el caso del hospital de la Misericordia de Bérgamo y 1643 en las propiedades del arzobispado de Brescia. Es más, durante la segunda mitad del siglo XVII en dicho arzobispado se observa ya un fuerte y general crecimiento de la producción de maíz: si en 1655 ésta fue de apenas 22 hectolitros, en 1714 alcanzó los 277 hectolitros, superando así al trigo, cuya cosecha que se situó en ese año en torno a los 174 hectolitros. Una tendencia muy similar se registra, y ello no deja de sorprendernos, en las granjas localizadas en las zonas de regadío, las cuales reunían mejores condiciones para poner en práctica una agricultura destinada a atender las necesidades de los mercados urbanos. Al respecto, y según la contabilidad del hospital de Brescia, en ellas pasaron de recogerse 573 hectolitros de trigo y 103 de maíz en 1680, a 718 y 607 de trigo y maíz, respectivamente, en 1744, y de ahí a 320 y 908 hectolitros, también respectivamente, de trigo y maíz a finales del siglo XVIII (Coppola, 1979). Igual sucede en la parte occidental de Lombardía, en la conocida como «patria» de la agricultura capitalista (Zaninelli, 1964, pp. 119-120). En esta zona, cuya agricultura es muy avanzada, en el curso del siglo XVIII el precio del maíz llegó a igualar al del trigo en los mercados locales (Zaninelli, 1964, p. 130). En este escenario no sorprende que el catastro introducido en el Estado de Milán por Carlos VI en la década de 1720, advierta que la planta ocupaba entre un 12 y un 16\% del suelo de regadío y entre un 30 y un 35\% del suelo de secano (Faccini 1988, p. 197), lo que, de por sí, es un claro indicador de que era un cereal ampliamente vendido y comercializado. 
Por su parte, y a la luz de la documentación privada, en Umbría el avance del maíz también presenta otra cronología. En los libros de contabilidad del Pío Colegio de la Universidad de Perugia, aparece por primera vez consignado en $1766^{1} \mathrm{y}$ en las propiedades de la familia noble Bourbon di Sorbello en 1806; unas propiedades, en las cuales se registra además con el nombre de 'trigo siciliano'². Otra pista de la tardía penetración de este cultivo en las grandes explotaciones agrícolas de la región nos la da lo sucedido en las tierras de la familia Degli Oddi. Es en 1802 cuando se anota por primera vez la distribución entre sus campesinos de pequeñas cantidades de semillas de maíz, momento a partir del cual comienza a plantarse. También en el caso del gran patrimonio de la abadía benedictina de San Pietro de Perugia aparece regularmente a partir de $1816^{3}$.

Como ya se ha señalado, son evidentes pues las discrepancias cronológicas entre el instante en que se produce la aparición del maíz en los mercados de las ciudades de Umbría, lo que ocurrió durante la segunda mitad del siglo XVIII, y el momento de su consolidación como cultivo en las granjas y explotaciones agrícolas de la región. Recordémoslo, si el maíz llega a los mercados de Gubbio y de Asís hacia mediados de la centuria, deberemos esperar en cambio a los primeros años del siglo XIX para tener constancia de su presencia en el marco de las grandes empresas agrícolas.

Ante esta situación, que aconseja la realización de posteriores investigaciones al objeto de establecer la procedencia del maíz que se vendía en los mercados urbanos, el único dato seguro es la consolidación tardía, irregular, pero rápida, de su cultivo en Umbría una vez iniciado el siglo XIX, al punto de hacer de la alternancia trigo / maíz el pivote de la agricultura regional en los albores de la edad contemporánea (Vaquero Piñeiro-Giommi, 2017). No debió ser pues una mera casualidad que la población de Umbría hubiese crecido un 88\% entre 1802 y 1911 (Bonelli, 1967, p. 29). Detrás de este crecimiento, seguramente, estén los efectos reales y psicológicos que en la población rural produjo la generalización de una planta, cuyos altos rendimientos contribuyeron a alejar de la mentalidad colectiva el fantasma de la carestía y el hambre.

\section{Los precios del maíz en Lombardía y Umbría (1700-1861)}

Estudiando la evolución de los precios y salarios de Milán durante el siglo XVIII, Aldo de Maddalena llamaba la atención acerca de la importancia que tuvo «la inclusión del maíz en la órbita de la oferta y de la demanda de cereales» (De Maddalena, 1974,

Archivio Collegio Pio della Sapienza di Perugia, Libri dell'entrata e uscita, 1766-1784.

Archivio di Stato di Perugia, Archivio Bourbon di Sorbello, serie I, 59.

Archivio Monastero di San Pietro di Perugia, LE, 409. 
p. 108). Como es sabido, el comportamiento de los precios del trigo ha permitido a los historiadores la elaboración de detalladas series por medio de las cuales han procedido luego a individualizar la correlación existente entre los distintos ciclos económicos y demográficos (Romano, 1967). Al respecto, y sin abandonar el contexto italiano, bastaría con recordar los fundamentales estudios de autores como Eugenio Parenti, Ruggiero Romano, Aldo de Maddalena o Paolo Malanima, por citar tan sólo algunos nombres (Parenti, 1942; Romano, 1965; De Maddalena, 1974; Malanima, 1976). Este es un interés que, desde otros planteamientos teóricos y perspectivas historiográficas, permanece vivo, tal y como lo demuestran los trabajos llevados a cabo sobre la relación existente entre la evolución de los precios, la integración de los mercados y la acción de las instituciones (Persson, 1999; Epstein, 2000; Allen 2001).

No obstante, y a la luz de lo que se ha escrito sobre el tema, es evidente que la mayoría de los especilistas sigue utilizando el trigo como el indicador principal, a veces casi como el único, de sus observaciones, cuando hoy está firmemente establecido que era un cereal cuyo consumo se realizaba principalmente en las grandes ciudades. Lo cierto es que para tener una visión más completa sobre el funcionameinto de los mercados urbanos, debemos desplazar nuestra mirada hacia las ciudades más pequeñas, en las cuales es posible observar el peso real que tenía el consumo de maíz y de los cereales menores, a menudo poco o nada utilizados en los estudios sobre los niveles de vida y el poder adquisitivo de los salarios. Así, si en Milán el consumo del trigo se situaba por encima del $80 \%$ del total del cereal presente en el mercado, en Como este porcentaje era en cambio de un $50 \%$ en los años normales, descendiendo considerablemente en los de crisis ante el empuje del maíz. En la misma línea, en las comunidades de montaña y en las poblaciones más alejadas de los principales circuitos comerciales, lo normal era que el maíz cubriese hasta el 80-90\% del consumo de cereales.

Ante esto, es evidente que resulta esencial proceder a la reconstrucción del comportamiento de los precios del maíz. Algo que puede hacerse desde finales del siglo XVII en Lombardía y desde la primera mitad del siglo XVIII en Umbría. Un empeño, no obstante, preñado de dificultades. La primera, es reconstruir la evolución de los precios de todos los cereales y, por lo tanto, sopesar el nivel de sincronía de los mercados. La cuestión no es baladí, pues son muchos los estudios que insisten en que la integración efectiva de los mercados sólo se alcanzó tras la llegada del ferrocarril, el cual creó una red de transportes capaz de superar las barreras impuestas por las divisiones políticas. Aun así, y como veremos, las tendencias que presentamos ofrecen un alto nivel de homogeneidad. La segunda dificultad, se refiere a la interacción que hubo entre los precios del maíz y el trigo, lo que implica hacerse varias preguntas. Por ejemplo, ¿cuál es la relación existente entre los precios de ambos cereales? ¿Es 
seguro que el precio del trigo fue siempre superior al del maíz? ¿Es posible identificar movimentos y elementos de complementariedad entre ellos? ¿Cómo se comportan los precios durante las crisis alimentarias? ¿Es cierto que el maíz contribuyó a estabilizar los precios, ya que su valor crecía menos que el del trigo? Preguntas a las que intentaremos dar alguna respuesta en este trabajo.

\section{Gráfico 1. Precio del staio de maíz en los mercados de cereales de Asís, Orvieto, Gubbio, Cortona y Castiglione Fiorentino, 1726-1861. Índice medio}

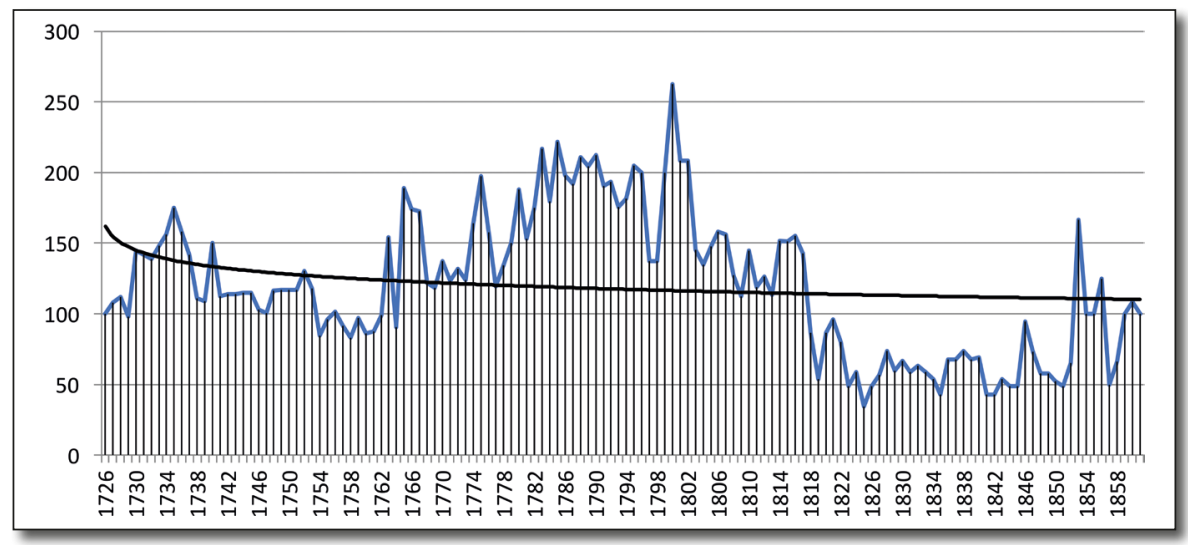

Fuente: escudos/staio, Orvieto (De Santis, 1994-95) y Asís (Aristei, 1996-97); libras/staio, Cortona (Cipollini, 2001-02) y Castiglione Fiorentino (Polvani, 1999-2000).

Antes de comenzar, recordar al lector, que los datos estadísticos que poseemos para la región de Umbría son aun parciales, puesto que esta es una investigación que todavía está en marcha. Dicho esto, y dejando a un lado el problema que supone tener que manejar a un tiempo diferentes monedas y unidades de peso y medidas, en el gráfico 1 se aprecia la perfecta sincronía existente entre los distintos mercados examinados. Es más, es posible identificar en ellos algunas fases, como entre 1700 y 1780, cuando se detecta un largo período en el que los valores de mercado fueron bastante estables, con la excepción de en dos episodios críticos: 1765-1767 y 1774-1775.

Ya más en detalle, sabemos que en Asís el precio medio del staio $^{4}$ de maíz fluctuó entre 1741 y 1764 alrededor de los 3,69 escudos de moneda, para rozar los 5 entre 1765 y 1767 . Una vez superada la crisis de subsistencia de los años sesenta (Gori, 1989, p. 573), el staio descendió hasta los 3,5 escudos, salvo en el bienio 1774-1775, cuando la línea general de precios vuelve a subir hasta los 6-6,6 escudos. Entre 1778 y 1798 los precios promedio de este mercado urbano comenzaron a subir, alcanzando

$4 \quad$ En los Estados Pontificios, un staio de cereal equivalía a 24,538 litros. 
los 5,68 escudos, lo que significa un aumento del 54\% con respecto a lo sucedido en los años centrales de siglo.

La tendencia que diseñan estos datos puede compararse sin problemas con la que encontramos en el municipio de Gubbio, donde también se aprecia una fase de estabilidad hasta 1765 (en 1727-1765 el precio promedio anual del maíz fue de 77,9 baiocchi $^{5}$ la mina), para en 1766-1768 llegar a los 143 baiocchi, y bajar luego hasta 103,20 baiocchi en 1775.

En resumidas cuentas, entre mediados de los años setenta y los últimos años del siglo XVIII, en Gubbio y en Asís el precio del maíz experimentó un fuerte aumento: la mina de este cereal alcanzó en 1776-1797 un precio medio anual de 161,5 baiocchi, es decir, experimentó un aumento del 107\% en relación a la situación de mediados de siglo.

Los datos de los que disponemos nos permiten distinguir en las dos ciudades umbras, y antes de la ruptura que-produjo la llegada de las tropas francesas a la región en 1798, la existencia de al menos cuatro fases durante el siglo XVIII (Gráfico 1). La primera, de 1730 a 1764, se caracteriza por los precios estables y moderados; la segunda, está marcada por su crecimiento entre 1765 y 1768; la tercera, supone una vuelta a la normalidad, que duró aproximadamente hasta la segunda mitad de los años setenta. Y por último, un nuevo aumento de los precios en 1776-1778, el cual se prolongó hasta finales de la centuria estimulado por la invasión francesa. Ante esto, y más allá de cada caso particular, parece indudable que la tendencia alcista de los precios de los cereales registrada a lo largo de la segunda mitad del siglo XVIII habría supuesto un fuerte incentivo al aumento de la producción agrícola (Caracciolo, 1973, pp. 547-548). En estas circunstancias, nos resulta mucho más clara la penetración y extensión del maíz en los dos ámbitos regionales de estudio, incluso en aquellas tierras que eran poco adecuadas para su cultivo, como las de Umbría. Todo apunta pues a que el aumento de los precios habría estimulado la sustitución del barbecho tradicional y contribuido a la formación de una estructura agraria destinada a mantenerse viva hasta los cambios que se dieron en el curso de la segunda mitad del siglo XX.

Durante la dominación francesa, esto es, entre finales del siglo XVIII y principios del XIX, los datos disponibiles para los mercados analizados se hacen eco del enorme aumento que experimentó el precio del maíz. En Asís, el precio medio del staio entre 1798 y 1817 fue de 11,35 escudos, si bien se alcanzaron los 14 en 1800, 1801 y 1807 , e incluso los 16 en 1802 . Todo ello supuso una subida por encima del $127 \%$ si comparamos esta situación con la vivida a finales del siglo XVIII. Sólo en 1808-1811 se produjo una ligera tregua, aunque tendremos que esperar a 1818 a que se produzca un descenso significativo de los precios, cuando pasan a situarse en 6,80

100 baiocchi $=$ escudo nominal. 
escudos el staio. Pero, pese a que a partir de 1818 la caída del precio del maíz fue rotunda, su valor medio seguirá siendo siendo dos veces más alto que en las décadas centrales del XVIII.

Una evolución muy parecida se observa en el mercado de la ciudad toscana de Castiglione Fiorentino. En este caso, entre 1794 y 1801 el precio del staio de maíz osciló en torno a las 6,66 libras, un aumento de un 64\% con respecto al promedio de 4,05 libras de los años anteriores. La tendencia es muy similar a la de la ciudad de Asís, con una contracción en 1801 y un fuerte aumento entre 1810 y 1816 , cuando se alcanzaron las 6 libras por cada staio de maíz. En 1817 se inauguró una fase de precios bajos, que se mantuvo hasta el nacimiento del Reino de Italia, en 1861. La única excepción fue lo sucedido en los años 1853-1856, en los cuales el precio del staio de maíz se situó entre las 9 y las 11 libras.

Durante el siglo XIX, encontramos precios similares en los mercados de las ciudades de Cortona, Orvieto y Sarteano. Resumiendo casi hasta la caricatura, a la fase de precios ascendente registrada entre finales del siglo XVIII y 1817, con un paréntesis de caída en 1804-1810, le siguen una serie de décadas cuyo perfil predominante es el de la estabilidad y los precios bajos, salvo si exceptuamos unos pocos años de aumento de éstos (1828-29, 1838-39, 1853-54). En este sentido, cabe destacar la fuerte sincronía cronológica que existe entre los distintos mercados urbanos analizados, máxime cuando sabemos que pertenecen a dos estados distintos — el Gran Ducado de Toscana y los Estados Pontificios - que aplican políticas económicas diferentes. Algo que, sin lugar a dudas, nos indica que se produjo un funcionamiento integrado de los circuitos comerciales del maíz al margen de las barreras políticas existentes, basta con ver la tendencia convergente de los precios tanto dentro como fuera de los confines regionales considerados.

Los años de ocupación francesa supusieron para la evolución de los precios la entrada en una fase de considerable aumento, cuyo origen se sitúa en el estado de guerra que se vivió en Italia con la llegada de las tropas imperiales. También, en las malas condiciones climatológicas derivadas de la erupción del Tambora en 1815, pues la nube de cenizas y polvo arrojada por el volcán indonesio dio lugar al llamado «año sin verano», que en muchas regiones europeas se tradujo en una drástica reducción de las cosechas y, por consiguiente, en un aumento de la mortalidad (Fornasin, Breschi, Manfredini, 2015). Entre los factores que incidieron sobre la evolución de los mercados, conviene no olvidar que el precio más alto del período de ocupación francesa se registra, y no sólo en Lombardía, en 1800-1801, coincidiendo con el incremento que en la región experimentaron los salarios. En Milán, casi todos los grupos profesionales urbanos conocieron entre 1800 y 1805 una subida en sus respectivos salarios, y hubo casos en los que hasta se multiplicaron por dos. La razón fue el aumento de la oferta de 
trabajo (Pecchio, 1830, p. 44). Algo parecido se aprecia también en la Toscana, donde a pesar del elevado precio del trigo, el consumo de pan no descendió ya que el poder adquisitivo de los salarios y de las rentas continuó siendo alto (Paolini, 1827, p. 349). Por otro lado, y al hablar de los precios, conviene no olvidar los efectos de la inflación sobre su tendencia alcista, de la misma manera que la presión que a comienzos del siglo XIX se produjo sobre los alimentos a causa de las requisas realizadas por los franceses al objeto de abastecer sus tropas. A todos estos factores, y actores, se unen asimismo años de cosechas que si bien no fueron catastróficos, tampoco son excesivamente buenos. En definitiva, sobre esta suma de circunstancias, se originaron las condiciones que explican los precios muy altos de la época, en particular, en las ciudades, protegidas en esos instantes de los mismos por las políticas de racionamiento puestas en práctica.

Tomando como punto de referencia la abundante producción histórica disponible sobre la integración de los mercados en el Antiguo Régimen, es obvio que lo que sucede en Umbría y Lombardía durante los siglos XVIII y XIX encuentra total sintonía con lo que ocurre por las mismas fechas en muchas otras ciudades italianas y europeas (Herranz Loncán, 2016; Strangio, 2015). Aunque sabemos que el movimiento de los precios a largo plazo no puede ser explicado únicamente recurriendo a los fenómenos locales (Vivanti, 1967), resulta innegable que en las regiones de Lombardía y UmbríaToscana, éstos son capaces de hacer salir a la luz una imagen del mismo que posee no pocas similitudes con lo que estaba ocurriendo al respecto en otros lugares de Italia y Europa (Abel, 1976, pp. 331-347).

\section{Gráfico 2. Precio del rubbio de trigo, del 'trigo siciliano'y del maíz en Orvieto, 1801-1860. Índice medio}

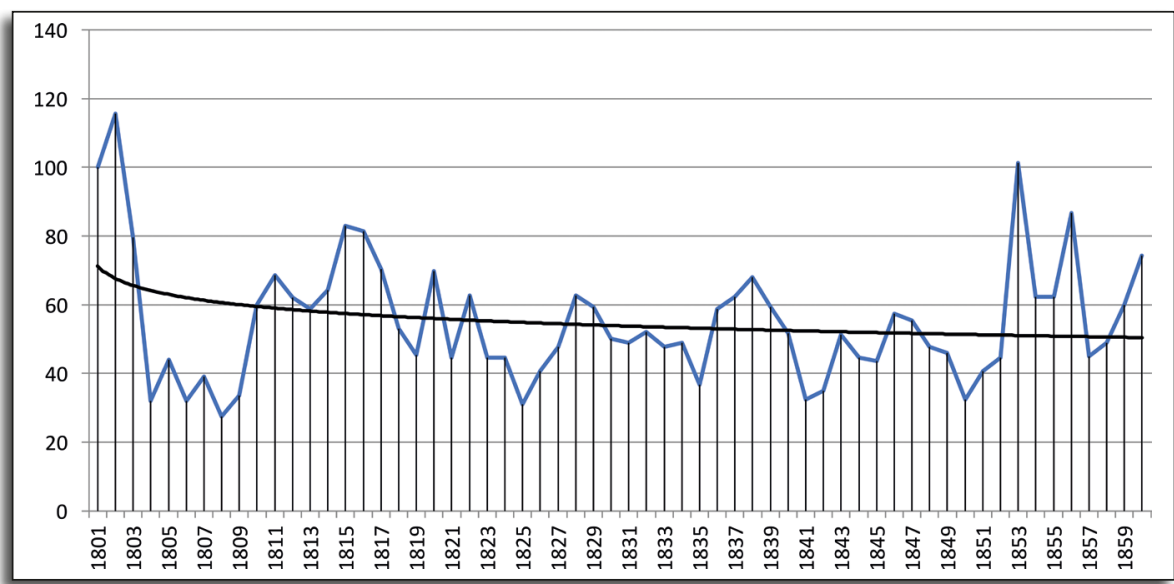

Fuente: De Santis, 1994-1995. 
Tabla 1. Precio medio del trigo, del 'trigo siciliano' y del maíz en Orvieto, 1801-1860 (Escudos/rubbio)

\begin{tabular}{|c|c|c|c|}
\hline Años & Trigo & Trigo siciliano & Maíz \\
\hline $1801-1805$ & 14 & 13 & \\
\hline $1806-1809$ & 7 & 5 & 6 \\
\hline $1810-1817$ & 13 & 8 & 5 \\
\hline $1818-1850$ & 8 & 5 & 7 \\
\hline $1853-1860$ & 10 & 7 & \\
\hline
\end{tabular}

Fuente: De Santis, 1994-95.

En cuanto a lo sucedido en las regiones de estudio con el movimiento de los precios de los diferentes cereales, comprobamos que lo acontecido en Umbría invita a una amplia reflexión sobre el asunto. Partiendo de la ciudad de Orvieto, para la cual contamos con los precios del trigo, del ‘trigo siciliano' y del maíz entre los inicios del siglo XIX y 1861, apreciamos que el aumento y la contracción de los precios van en paralelo durante la primera mitad del XIX (Tabla 1 y Gráfico 2). De este modo, se confirma que, e independientemente de las distintas políticas de control adoptadas por los estados italianos en la fase anterior a la Unidad, los precios de los cereales se comportan como si existiese un único mercado (Pescosolido, 2007).

Por el momento, ir más allá de estas cifras es muy poco seguro, pero si atendemos a lo que occurría en Sarteano, localidad situada en la frontera entre Toscana y los Estados Pontificios (Mapa 1), comprobamos que de 1780 a 1835 la trayectoria de los precios del trigo y del maíz evoluciona en paralelo, con oscilaciones ascendentes y descendentes perfectamente sincronizadas que nos permiten reconocer la existencia de hasta cinco fases (Tabla 2).

Tabla 2. Precio medio del trigo y del maíz en Sarteano, 1780-1835 (Staio/denari)

\begin{tabular}{|c|c|c|c|}
\hline Años & Trigo & Maíz & Diferencia precio trigo/maíz \\
\hline $1780-1792$ & 1.097 & 581 & $+47 \%$ \\
\hline $1793-1803$ & 2.033 & 1.467 & $+28 \%$ \\
\hline $1804-1810$ & 1.346 & 720 & $+46 \%$ \\
\hline $1811-1817$ & 2.181 & 1.370 & $+37 \%$ \\
\hline $1818-1835$ & 974 & 553 & $+43 \%$ \\
\hline
\end{tabular}

Fuente: Aggravi, 1999-2000.

En conjunto, y tras un período de precios no muy altos que dura hasta 1792, en los mercados de las ciudades estudiadas se producen aumentos notables de los mismos entre 1793 y 1803 (de un 85\% para el trigo y de un 152\% para el maíz), seguidos de una pausa hasta 1810 y luego de otro fuerte ascenso en 1811-1817 (de un 62\% para el trigo y de un 90\% para el maíz). Con el inicio de la Restauración (1815) los precios vuelven a estabilizarse en niveles similares a los de la década de 1780 . 
Además de la perfecta sincronía registrada en todos estos años en las diferentes ciudades consideradas entre los momentos de auge y caída de los precios del trigo y del maíz, en las fases más críticas - 1793-1803 y 1811-1817- la distancia entre los precios de ambos cereales se reduce, básicamente, porque el maíz sufre un ascenso más agudo. Si en los tres períodos que podemos definir de normalidad relativa - 1780-1792, 1804-1810 y 1818-1835 - la diferencia entre el precio medio del trigo y del maíz oscila entre un $43 \%$ y un 47\%, en los años de mayor inestabilidad - 1793-1803 y 1811-1817ese porcentaje se cae a un 28\%-37\%. Estos porcentajes confirman la mayor estabilidad del precio del trigo en los periodos de crisis, y viceversa, visto que los precios de los otros cereales presentan oscilaciones mucho más profundas. Como se desprende de las investigaciones disponibles para el caso francés e italiano, la razón de esto estriba en que durante las carestías y crisis de abastecimiento los cereales secundarios sufren las consecuencias tanto de la oferta que se dirige hacia el cereal más caro y prestigioso, como del alza de los precios que penaliza los alimentos más baratos (Labrousse, 1932; Malanima, 1976; Gori, 1989, p. 573). Así, en los años de carestía, muchos pequeños agricultores, capaces en condiciones normales de obtener lo necesario para el consumo familiar, pasan a depender del mercado, lo que contribuye al aumento de los precios. El impacto de esta demanda adicional es palmario en el caso del maíz, cuyos precios se disparan durante la crisis en mayor medida que los del trigo, no sólo porque forma parte de la dieta de las familias campesinas, sino también por el aumento de su consumo en las ciudades ante el rápido encarecimiento de la harina de trigo.

No obstante, siempre hay excepciones que nos advierten de que nos encontramos ante una cuestión que presenta muchos perfiles y matices. En el mercado de Castiglione Fiorentino, como va dicho, una ciudad toscana situada cerca de los Estados Pontificios (Mapa 1), la situación es bastante diferente y no por la tendencia de los precios, que es muy similar a la de Sarteano (Tabla 3), sino porque en Castiglione Fiorentino se registra una mayor estabilidad entre los precios del maíz y del trigo, e incluso en épocas de gran tensión, el maíz resulta ser una mercancía bastante accesible, sin que su costo presente grandes variaciones en el tiempo. Es probable que éste sea un mercado urbano que ha logrado mantener un suministro regular de maíz a precios constantes y estables entre 1793-1798 (4 libras el staio) y 1818-1861 (3 libras el staio), pero también, que en él su demanda no haya sido muy elevada, visto que durante todo el período analizado los precios del trigo fueron el doble que los del maíz.

La situación que nos encontramos en la zona lombarda es diferente. Aquí, el incremento del consumo de maíz implica que durante los periodos de crisis su precio se acerca, e incluso supera, al del trigo. Al respecto, es ejemplar lo sucedido en el mercado de Desenzano, una ciudad de más de 60.000 habitantes que consumía casi exclusivamente maíz y que era además un punto neurálgico para el abasto de una am- 
Tabla 3. Precio medio del trigo y del maíz en Castiglione Fiorentino, 1793-1861 (Staio/libras)

\begin{tabular}{|c|c|c|c|}
\hline Años & Trigo & Maíz & Diferencia precio trigo/maíz \\
\hline $1767-1792$ & 5 & & $+46 \%$ \\
\hline $1793-1798$ & 7 & 4 & $+55 \%$ \\
\hline $1799-1803$ & 11 & 5 & $+50 \%$ \\
\hline $1804-1810$ & 6 & 3 & $+60 \%$ \\
\hline $1811-1817$ & 10 & 4 & $+57 \%$ \\
\hline $1818-1861$ & 7 & 3 & \\
\hline
\end{tabular}

Fuente: Polvani, 1999-2000.

plia área de montaña formada por la zona del lago de Garda y los valles del Trentino (Tabla 4). En el curso de la crisis, los precios de estos cereales llegaron casi a tocarse, tal y como por ejemplo ocurrió en septiembre y diciembre de 1782, cuando el precio medio del trigo fue de 54,22 libras por soma y el del maíz de 53 libras, mostrando así entre ambos una diferencia mínima del $2 \%$. Incluso en momentos excepcionales, los precios máximos del maíz superaron a los del trigo. Sin ir más lejos, esto sucedió en julio de 1764, con 44 libras la soma, y en julio de 1794, con 64,10 libras, las cuales estaban ligeramente por encima de las 63 libras que costaba el trigo. Estos fueron los precios más altos de todo el siglo para ambos cereales (Vivanti, 1967, p. 423).

Asimismo, la gran difusión del maíz en el área lombarda dio lugar a un notable aumento de las cantidades de cereal vendidas. Si en el siglo XVII, el monto total vendido en el mercado de Garda fue de 66.366 libras, en el siglo XVIII este umbral se superó al menos en quince ocasiones, situándose el valor más alto en 1792, cuando se vendieron 93.103 some de maíz ${ }^{6}$.

Tabla 4. Precios mínimos y máximos de los cereales en el mercado de Desenzano, 1794

\begin{tabular}{|l|c|c|c|c|c|}
\hline Mes & Trigo & Mijo & Arroz & Maíz & $\begin{array}{c}\text { Días mensuales } \\
\text { de mercado }\end{array}$ \\
\hline Enero & $64-67,10$ & $47-51$ & 7,10 & $52-56,10$ & 4 \\
\hline Febrero & $63-68$ & $47-50$ & $7-7,10$ & $53-56$ & 4 \\
\hline Marzo & $61-67$ & $48-51$ & $6,15-7$ & $54-56,10$ & 4 \\
\hline Abril & $56-61$ & $43-49$ & $6,10-6,12$ & $55-58,10$ & 5 \\
\hline Mayo & $56-60$ & $43-47$ & $6-6,10$ & $53-58,10$ & 4 \\
\hline Junio & $62-65$ & $48-50$ & 6,10 & $58-64$ & 4 \\
\hline Julio & $54-63$ & $48-52,1$ & 6,7 & $54-64,1$ & 5 \\
\hline Agosto & $49-54$ & $30-36$ & 6,10 & $34-37$ & 4 \\
\hline Septiembre & $52-58$ & $30-35$ & $6,10-7,10$ & $31-36$ & 5 \\
\hline Octubre & $53-63$ & $27-33$ & $7-7,15$ & $32-37$ & 4 \\
\hline Noviembre & $61-64$ & $27-32$ & $7-7,10$ & $31-35$ & 4 \\
\hline Diciembre & $61-65$ & $29-32,1$ & $6,10-7,10$ & $31-35$ & 5 \\
\hline
\end{tabular}

Fuente: Archivio della Comunità di Riviera - Saló, b. 496, fasc. 162.

Agradecemos a Rodolfo Bertoni habernos facilitado esta información. 
Ante estos datos cabe la posibilidad de preguntarse si se puede establecer una relación entre el nivel de precios y la cantidad de cereales disponibles en el mercado o, y dicho de otra manera, si los precios son una variable que no depende exclusivamente de las cantidades vendidas en el mercado. Por ejemplo, el mencionado mercado de Desenzano da fe de la existencia de precios altos al margen de la disponibilidad efectiva de cereal. En 1777, año en que se comercializaron 68.689 some de trigo, sus precios oscilaron entre un mínimo de 32 y un máximo de 40 libras la soma, los mismos valores que se registraron en 1759 , cuando se vendieron un total de 80.139 some. En la misma línea, en la primavera de 1782 los precios comenzaron a aumentar rápidamente a pesar de la presencia de grandes cantidades de maíz en los almacenes de la ciudad.

Ejemplos como estos se convierten en pistas de investigación que podrían confirmarnos que, y al margen de la solidez del suministro, los precios podían estar afectados por la existencia de una fuerte demanda tanto interna, en cada ciudad, como externa, lo que en este último caso confirmaría la existencia de un mercado relativamente integrado de cereal a nivel regional. Así, los altos valores documentados en el mercado de Cuneo en 1765, nos indican que, y a pesar de la enorme disponibilidad de cereales, sus precios dependían de las grandes cantidades de trigo enviadas al Reino de Nápoles para paliar los efectos de una grave crisis frumentaria.

\section{El maíz en las haciendas agrícolas de Umbría}

No podemos terminar este trabajo sin hacer mención al papel jugado por la oferta de cereales, algo que implica detenernos en el estudio de la producción y el comportamiento que al respecto mostraron los grandes proprietarios agrícolas. Aunque todavía nos queda mucho camino por recorrer en este punto, vista la fragmentación de la documentación contable de las haciendas, estamos en condiciones de presentar algunos datos relativos a la realidad agrícola de Umbría a lo largo del siglo XIX. Emplearemos para ello la información de la hacienda «Casalina», perteneciente al monasterio benedictino de San Pietro di Perugia (Tabla 5).

A través de la información que nos proporciona, apreciamos entonces que entre 1816 y 1861 la cosecha anual de trigo y maíz fue en ella de aproximadamente de unos 2.960 staia, siendo el cereal más importante el trigo, que suponía el 63\% del total. Obviamente, en esos años se produjeron fluctuaciones anuales en la producción, si bien el porcentaje del maíz en el total de la misma osciló entre un mínimo del 14\% en 1817 y un máximo del $63 \%$ en 1844 , pero, más allá de estos dos puntos extremos, se situó siempre entorno al 37\%-44\% de los cereales cosechados. 
Tabla 5. Cosecha de trigo y maíz en la granja «Casalina» del monasterio de San Pietro di Perugia, 1816-1861 (Staio)

\begin{tabular}{|c|c|c|c|c|}
\hline Año & Trigo & Maíz & Total & \% maíz respecto al total \\
\hline 1816 & 2.113 & 808 & 2.921 & 28 \\
\hline 1817 & 3.507 & 572 & 4.079 & 14 \\
\hline 1818 & 2.515 & 1.019 & 3.534 & 29 \\
\hline 1841 & 1.916 & 870 & 2.786 & 31 \\
\hline 1842 & 2.135 & 1.593 & 3.728 & 43 \\
\hline 1843 & 1.312 & 1.052 & 2.364 & 44 \\
\hline 1844 & 1.312 & 1.052 & 1.656 & 63 \\
\hline 1845 & 892 & 737 & 1.629 & 45 \\
\hline 1846 & 854 & 475 & 1.329 & 36 \\
\hline 1847 & 1.894 & 1.186 & 3.080 & 38 \\
\hline 1848 & 1.392 & 823 & 2.215 & 37 \\
\hline 1849 & 2.484 & 1.121 & 3.605 & 31 \\
\hline 1850 & 2.850 & 1.650 & 4.505 & 37 \\
\hline 1861 & 2.542 & 1.477 & 4.019 & 37 \\
\hline Media & 1.966 & 994 & 2.960 & \\
\hline
\end{tabular}

Fuente: Archivio monastero di San Pietro (Perugia), LE, 409 e 410.

En otras haciendas agrícolas umbras, el maíz tenía más importancia, aunque no siempre sea posible hacerse una visión clara de ello, pues los censos agrarios disponibles para la primera mitad del siglo XIX, y siguiendo la pauta imperante en el siglo anterior (Chiacchella, 1996; Biagioli, 1975), sólo indican genéricamente la existencia de tierras dedicadas al cultivo de cereal, sin especificar ni la cantidad ni la tipología de lo sembrado (Bonelli, 1967, p. 154). Si pasamos a continuación a ver lo sucedido en las tierras propriedad de los marqueses Bourbon di Sorbello, encontramos que en ellas la producción de maíz tenía mucha mayor cabida (Tabla 6).

Tabla 6. Cosecha de trigo y maíz en la hacienda agrícola de los marqueses Bourbon di Sorbello, 1809-1820 (Staio)

\begin{tabular}{|c|c|c|c|c|}
\hline Año & Trigo & Maíz & Total & \% maíz respecto al total \\
\hline 1809 & 1.710 & 1.242 & 2.952 & 42 \\
\hline 1811 & 704 & 1.164 & 1.868 & 62 \\
\hline 1812 & 1.770 & 2.426 & 4.196 & 56 \\
\hline 1816 & 1.924 & 1.406 & 3.330 & 42 \\
\hline 1818 & 2.296 & 2.198 & 4.494 & 49 \\
\hline 1819 & 2.258 & 2.966 & 5.224 & 57 \\
\hline 1820 & 1.676 & 3.346 & 5.022 & 67 \\
\hline Media & 1.762 & 2.107 & 3.869 & 54 \\
\hline
\end{tabular}

Fuente: Archivio di Stato di Perugia, Archivio Bourbon di Sorbello, serie I, n59, 10. 
A pesar de las diferencias existentes de hacienda a hacienda, en las granjas de los mencionados marqueses Bourbon di Sorbello, el maíz representaba a principios del siglo XIX el 54\% del total del cultivo de cereal, con picos que oscilaron entre el $62 \%$ y el $67 \%$ en 1811 y 1820 . Es este un perfil destinado a mantenerse en el tiempo, ya que de 1868 a 1879 el maíz continuó siendo el 55\% de lo cosechado en las tierras de esta familia perteciente a la nobleza de Perugia. Un caso que, cuando menos, certifica la relevante función asignada a su producción a comienzos del siglo XIX, aunque, y a pesar de ello, no nos sea posible obviar las diferencias encontradas al respecto entre las haciendas de los grandes propietarios. En este sentido, y para comprender mejor sus estrategias de producción, la investigación debera seguir examinando en el futuro la contabilidad de otros patrimonios agrícolas de la misma naturaleza y envergadura. Será necesario, pues, prestar la debida atención tanto a la tendencia general resultante como a las estrategias que cada propietario y productor de cereales adoptó al objeto de amoldarse, o de subvenir, las políticas aduaneras impuestas en la época por los Papas (Pescosolido, 2004, pp. 100-102).

Por otro lado, no hay que perder de vista que la documentación de las grandes granjas agrícolas también nos brinda la posibilidad de estudiar en profundidad todos aquellos aspectos relacionados con la producción y la comercialización de cereales. La evidencia empírica de esto la tenemos en otra granja perteneciente al patrimonio raíz del monasterio de San Pietro, en los llamados «Bienes adyacentes», los cuales nos remiten a la existencia de una producción de cereales mucho más especializada de lo que en principio se pensaba para las primeras décadas del siglo XIX, ya que incluye trigo, maíz y 'trigo duro'. Comparando su volumen de producción con el de la granja «Casalina», resulta que la los «Bienes adyacentes» es mucho más reducida —entre 1824 y 1860, apenas 610 rubbi de trigo, 346 de maíz y 290 de ‘trigo duro' al año-, si bien, desde un punto de vista cualitativo, contempla al mencionado 'trigo duro', tradicionalmente destinado a la elaboración de pasta seca. Se trataría entonces de una agricultura relativamente especializada, dirigida al cultivo de un producto de una calidad superior a la del trigo normal.

Sin embargo, e independientemente de la evolución de la producción anual, el cultivo de varios tipos de cereal en una misma hacienda nos pone tras la pista de una agricultura que ya a comienzos del siglo XIX trataba de satisfacer varios tipos de demanda al mismo tiempo: la del consumo doméstico de las familias campesinas, la del monasterio, la de los mercados urbanos y, quizás, la del funcionamiento de las primeras fábricas de «pasta seca». Unas diferencias en la demanda que, lógicamente, se reflejan en los precios medios que tenían los distintos tipos de cereal. Así, en las granjas del monasterio de San Pietro el precio del rubbio de maíz era de 5,1 escudos, 
el de trigo de 7,7 escudos y el de 'trigo duro' de 8,28 escudos. Abanico de precios que era sufragado por la existencia de un mercado muy segmentado.

Finalmente, los datos procedentes de los archivos de los grandes productores de cereal nos permiten también hacer comparaciones directas entre los precios que predominaban en los mercados y en las unidades de producción, en las haciendas. En este caso, y al objeto de superar las dificultades impuestas por el uso de diferentes monedas y unidades métricas, hemos elegido la serie de precios del mercado de Orvieto. Los años que consienten esa comparación van de 1824 a 1860 y los resultados son sorprendentes, visto que el precio medio del maíz recogido en la granja «Bienes adyacentes» del monasterio de San Pietro de Perugia es de 5,1 escudos el rubbio, exactamente el mismo que el imperante en el mercado de Orvieto (Tabla 7). Por lo tanto, estamos en presencia de lo que parece ser un «precio único», lo que indicaría la existencia de relaciones de mercado extensas en el espacio y de una fuerte integración entre los distintos espacios comerciales (Malanima, 2009). Otras pistas halladas se encaminan en la misma dirección: el valor del rubbio de trigo en las granjas de la familia Bourbon di Sorbello entre 1825 y 1853 osciló en torno a los 8 escudos, en línea con el registrado en las haciendas agrícolas del monasterio de San Pietro de Perugia y en el mercado de Orvieto. Todos estos datos atestiguan que nos hallamos ante la formación de un espacio económico muy integrado en lo que respecta a la comercialización de los cereales y es evidente que en la construcción de este espacio comercial el maíz jugó un papel muy destacado.

Tabla 7. Precio medio del rubbio de trigo y de maíz, en escudos, en Orvieto y en las haciendas agrícolas del monasterio de San Pietro y de los marqueses de Bourbon di Sorbello

\begin{tabular}{|c|c|c|c|}
\hline Cereal & $\begin{array}{c}\text { Orvieto } \\
(\mathbf{1 8 2 4 - 1 8 6 0 )}\end{array}$ & $\begin{array}{c}\text { Monasterio de San Pietro } \\
(\mathbf{1 8 1 6 - 1 8 5 0 )}\end{array}$ & $\begin{array}{c}\text { Bourbon di Sorbello } \\
(\mathbf{1 8 2 5}-1853)\end{array}$ \\
\hline Trigo & 8,2 & 7,7 & 7,9 \\
\hline Maíz & 5,1 & 5,1 & 5,1 \\
\hline
\end{tabular}

Fuente: De Santis, 1999-2000; Archivio Monastero di San Pietro (Perugia), LE, 409 e 410; Archivio di Stato di Perugia, Archivio Bourbon di Sorbello, serie I, n59, 10 .

Como va dicho, el precio medio del rubbio del trigo en Orvieto entre 1824 y 1860 fue de 8,2 escudos, situándose así ligeramente por encima de los 7,7 escudos registrado en las propiedades del monasterio de San Pietro y de los 7,9 hallados en las tierras de los marqueses Bourbon di Sorbello (Tabla 7). Son diferencias mínimas, por lo que no dejaremos de preguntarnos si estas coincidencias son resultado de una simple casualidad o si estamos ante una clara muestra de circuitos comerciales integrados ya en la primera mitad del siglo XIX. Al respecto, contamos con más información que corroboraría esta última posibilidad. Si atendemos al precio del 'grano 
de Sicilia', que con toda probabilidad sería maíz, apreciamos entonces que su costo medio en las granjas de los Bourbon di Sorbello fue de 5,1 escudos, que es el mismo precio documentado para el mismo tipo de cereal en las propiedades de la abadía de San Pietro y en el mercado de Orvieto.

En suma, a la vista de estos datos y de las conclusiones a las que llega la bibliografía especializada acerca del funcionamiento de los mercados preindustriales, cabe concluir que el maíz, tras una larga y progresiva penetración en la economía rural y urbana, contribuyó de forma decisiva a la integración de los mercados. Por supuesto, esto no significa negar en ello el peso que tuvieron los factores locales, si bien, la información recogida hasta la fecha sobre la dinámica comercial previa al nacimiento del reino de Italia apunta a la existencia del alto grado de integración y convergencia que se daba en los mencionados mercados ya al inicio del siglo XIX.

\section{Conclusión}

El maíz llegó a la Península Italiana a principios del siglo XVI y tras una fase de asimilación cultural comenzó a difundirse con rapidez: desde el estado veneciano, a lo largo del valle del Po, pronto alcanzó Lombardía. Sin embargo fue en los siglos XVII y XVIII cuando logró su máxima expansión geográfica, al punto de consolidarse en las regiones del centro de Italia - Toscana, Umbría y las Marcas - e, incluso, penetrar en la agricultura de las zonas más meridionales del país. Sobre estas cuestiones existe una abundante bibliografía, por lo que nosotros hemos preferido deternernos a estudiar el efecto que tuvo la «revolución del maíz» en el mercado urbano de los cereales.

Si hasta la llegada de la planta americana existía en las ciudades italianas un mercado en el que predominaban el trigo y una serie de cereales menores, es a partir del siglo XVI cuando esta tradicional estructura de la oferta comienza a cambiar. La alimentación dejó de depender exclusivamente del trigo, al tiempo que en los campos se redujo paulatinamente el espacio reservado al cultivo de los cereales menores. Un aspecto importante de este «nuevo» mercado que ahora se configuraba fue su alto nivel de complementariedad, tal y como lo demuestra la evolución sincronizada de los precios. En este sentido, los datos aportados ponen de manifiesto que en la Italia moderna, el maíz se consolidó en los circuitos comerciales hasta ocupar un puesto insustituible en los mercados urbanos, sea de la pequeñas o de las grandes ciudades.

Aunque en el trabajo avanzamos resultados de una investigación todavía en marcha, la información que nos aportan aconseja que, en el futuro, cuando se procedan a estudiar el funcionamiento y el comportamiento de los mercados cerealícolas de las ciudades preindustriales, se considere el papel jugado en ellos por el maíz. Un cultivo que, si bien es cierto servía para el autoabastecimiento de las familias campesinas, 
llegó a ser un alimento importante para la población urbana. De ahí que se deba seguir estudiando la penetración y de los efectos del maíz en los mencionados mercados.

Por último, la realidad histórica que esos resultados dejan al descubierto nos indicant que si por un lado es necesario profundizar y ampliar nuestro conocimiento sobre la evolución de la producción y de los precios, por otro, resulta imprescindible analizar la contabilidad de las haciendas agrícolas, para de este modo hacernos con una visión más completa del problema. Sólo así será posible apreciar la estrecha relación que hubo entre los grandes circuitos comerciales del cereal — que atendían la demanda-, y las pautas de explotación aplicadas por los grandes y pequeños propietarios — que buscaban ampliar su producción-. En el estado actual de nuestros conocimientos, sabemos que el maíz redujo el espacio dedicado al cultivo de los cereales menores, pero también que no llegó a sustituirlos complemente. Más bien, todo apunta a que en cada explotación se creó un equilibrio entre los distintos cultivos, el cual se caracterizó por su franca capacidad para amoldarse a la coyuntura y al contexto socio-económico de la época. En suma, y a lo largo de la edad moderna, el maíz contribuyó en Italia a la formación de un mercado alimentario flexible, que supo adaptarse a la demanda tanto de la población urbana como de la rural. 


\section{Bibliografia:}

ABEL, Wilhelm (1976), Congiuntura agraria e crisi agrarie. Storia dell'agricoltura e della produzione alimentare nell'Europa centrale dal XIII secolo all'età industriale, Torino, Einaudi.

Aggravi, Luca (1999-2000), I prezzi dei principali prodotti agricoli a Sarteano dal 1780 al 1835, Tesi di Laurea, Facoltà di economia e commercio, Università degli Studi di Perugia.

Alfani, Guido (2010), Il Grand Tour dei Cavalieri dell'Apocalisse. L'Italia del "lungo Cinquecento” (1494-1629), Venezia, Marsilio.

Ambrosoli, Mauro (1992), Scienziati, contadini e proprietari. Botanica e agricoltura nell'Europa occidentale 1350-1850, Torino, Einaudi.

ARISTEI, Luca (1996-97), I prezzi di alcuni prodotti agricoli ad Assisi dal 1741 al 1821, Tesi di Laurea, Facoltà di Economia e Commercio, Università degli Studi di Perugia.

AA.VV. (1992), Plantes et cultures nouvelles en Europe occidentale au Moyen Age et à l'époque moderne, Flaran, Centre culturel de l'Abbaye de Flaran.

Biagioli, Giuliana (1975), L'agricoltura e la popolazione in Toscana all'inizio dell'Ottocento, Pisa, Pacini.

BonElli, Franco (1967), Evoluzione demografica ed ambiente economico nelle Marche e nell'Umbria dell'Ottocento, Torino, Industria Libraria Tipografica Editrice.

CALINDRI, Giuseppe (1829), Saggio statistico storico del pontificio stato, Perugia, tip. Garbinesi e Santucci.

CAracciolo, Alberto (1973), "La storia economica”, en AA.VV., Storia d'Italia. Dal primo Settecento all'Unità, volume terzo, Torino, Einaudi, pp. 511-693.

CAZzola, Franco (2014), Contadini e agricoltura in Europa nella prima età moderna, Bologna, Clueb.

ChiacChella, Rita (1996), Ricchezza, nobiltà e potere in una provincia pontificia. La “misura generale del territorio perugino" del 1727, Napoli, Edizioni Scientifiche Italiane.

Cipollini, Silvia (2001-02), I prezzi dei principali prodotti agricoli a Cortona dal 1801 al 1859, Tesi di Laurea, Facoltà di Economia e Commercio, Università degli Studi di Perugia.

CopPola, Gauro (1979), Il mais nell'economia agricola lombarda (dal secolo XVII all'Unità), Bologna, Il Mulino.

CovA, Alberto (1992), “L'economia lombarda tra tradizione e innovazione: l'agricoltura”, en Fontana, Giovanni Luigi y Lazzarini, Andrea (eds.), Veneto e 
Lombardia tra rivoluzione giacobina ed età napoleonica. Economia, territorio, istituzioni, Milano-Bari, Cariplo-Laterza, pp. 25-44.

Cuocco, Vincenso (2008), "Viaggio in Molise", en Clerici, Luca (coord.), Scrittori italiani di viaggio, 1700-1861, volume primo, Milano, Mondadori, pp. 399- 426.

De Bernardi, Alberto (1984), "Pellagra, Stato e scienza medica: la curabilità impossibile", en Della Peruta, Francesco (ed.), Storia d'Italia. Annali 7. Malattia e medicina, Torino, Einaudi, pp. 681-704.

De Maddalena, Aldo (1974), Prezzi e mercedi a Milano dal 1701 al 1860, Milano, Banca Commerciale.

Demontis, Giorgio et al. (2009), Statistiche delle esplosioni nei cereali e valutazione del rischio [http://www.lulu.com/it/it/shop/giorgio-demontis/statistiche-delleesplosioni-nei-cereali-e-valutazione-del-rischio/ebook/product-22556286.html].

De SAnTis, Antonio (1994-1995), I prezzi dei principali beni di consumo ad Orvieto dal 1801 al 1861, Tesi di Laurea, Facoltà di Economia e Commercio, Università degli Studi di Perugia.

Desplanques, Henri (1969), Compagne sombriennes: contribution a l'etude des paysages ruraux en Italie centrale, Parigi, Armand Colin.

Doria, Andrea (2002), "Le colture del nuovo mondo", en Pinto, Giuliano et al. (eds.), Storia dell'agricoltura italiana. II. Il Medioevo e l'Età moderna, Firenze, Edizioni Polistampa, pp. 569-578.

Epstein, Stephan R. (2000), Freedom and growth. The rise of states and markets in Europe, 1300-1750, London-New York, Routldge. https://doi. org/10.4324/9780203183281

FACCInI, Luigi (1988), La Lombardia fra Seicento e Settecento. Riconversione economica e mutamenti sociali, Milano, Franco Angeli.

Federico, Giovanni (2007), "Market Integration and Market Efficiency. The Case of 19th Century Italy”, Explorations in Economic History, 44, 2, pp. 293-316. https://doi.org/10.1016/j.eeh.2006.02.003

FINZI, Roberto (2009), «Sazia assai ma dà poco fiato». Il mais nell'economia e nella vita rurale italiana, Bologna, Clueb.

FINZI, Roberto (1982), “Quando e perché fu sconfitta la pellagra”, en Betri, María Luisa et al. (eds.), Salute e classi lavoratrici in Italia dall'Unità al fascismo, Milano, Franco Angeli, pp. 391-429.

Fornasin, Alessio; Breschi, Marco e MANFredini, Matteo (2015), "Prime esplorazioni sugli aspetti meteorologici, economici e demografici del 1817 in Friuli", en Vaquero Piñeiro, Manuel et al. (eds.), «Moia la carestia». La scarsità alimentare in età preindustriale, Bologna, Il Mulino, pp. 215-236. 
FranCONIE, Hélène (1997), «Mais et millet dans les dialectes européens», Journal d'Agriculture Traditionelle et de Botanique Appliquée, 1, pp. 149-178. https:// doi.org/10.3406/jatba.1997.3606

Galli, Marika (2016), La conquête alimentaire du Nouveau Mondo. Pratiques et représentations franco-italiennes des nouveaux produits $d u X V \mathrm{I}^{\mathrm{e}}$ au XVIII siècle, Paris, L'Harmattan.

Gentilcore, David (2017), “The Impact of New World Plants, 1500-1800: The Americas in Italy", en Horodowich, Elizabeth et al. (eds.), The New World in Early Modern Italy 1492-1750, Cambridge, Cambridge University Press, pp. 190-205. https://doi.org/10.1017/9781316389034.011

GorI, Orsola (1989), "Mercato e prezzi del grano a Firenze nel secolo XVIII”, Archivio Storico Italiano, CXLVII, 3, pp. 525-623.

HeIne, Peter (2017), Delizie d'Oriente. Una storia della cultura gastronomica, Palermo, Sellerio.

HERRANZ LonCAN, Alonso (2016), "Una aproximación a la integración de los mercados españoles durante el siglo XIX”, en Gallego Martínez, Domingo et al. (eds.), Estudios sobre el desarrollo económico español. Dedicados al Profesor Eloy Fernández Clemente, Zaragoza, Prensas Universitarias de Zaragoza, pp. 313-333.

LABRousse, Ernest (1932), Esquisse du mouvement des prix et des revenusen France au XVIII siècle, 2 vols. Paris, Dalloz.

LEVI, Giovanni (1991), “L'energia disponibile”, en Storia dell'economia italiana. II. L'età moderna: verso la crisi, Torino, Einaudi, pp. 141-168

Malanima, Paolo (1976), “Aspetti di mercato e prezzi del grano e della segale a Pisa dal 1548 al 1818”, en Mirri, Mario (coord.), Ricerche di storia moderna, I, Pisa, Pacini, pp. 289-328.

Malanima, Paolo (2009), "Progresso o stabilità? Il mercato nelle economie preindustriali”, Studi Storici, L, 3, pp. 634-651.

Malanima, Paolo (2016), "Cibo e povertà nell'Italia del Sette e Ottocento", Rivista di Storia Economica e Sociale, I, pp. 1-25.

Malanima, Paolo, Wheat prices in Tuscany, 1260-1860, http://www.paolomalanima. it/default_file/Italian\%20Economy/Wheat_Prices_Tuscany.pdf.

MAntelli, Roberto (1998), “L'epoca della diffusione del mais. La mais coltura nell'evoluzione economica dell'Italia (fine XVI secolo - fine XIX secolo)", en Cavaciocchi, Simonetta (ed.), Prodotti e tecniche d'oltremare nelle economie europee. Secoli XIII-XVIII, Firenze, Le Monnier, pp. 451-465.

Messedaglia, Luigi (1927), Il mais e la vita rurale italiana. Saggio di Storia Agraria, Piacenza, Federazione Italiana dei Consorzi Agrari. 
MinECCIA, Francesco (1983), "Note sulle fattorie granducali del pisano occidentale nell'età moderna: Antignano, Casabianca, Collesalvetti, Nugola, S. Regolo e Vecchiano", en Coppola, Gauro (ed.), Agricoltura e aziende agrarie nell'Italia centro-settentrionale (secoli XVI-XIX), Milano, Franco Angeli, pp. 285-341.

MocARelli, Luca (2015), "Ripensare le crisi alimentari: lo Stato di Milano nel secondo Settecento", en Vaquero Piñeiro, Manuel et al. (eds.), «Moia la carestia». La scarsità alimentare in età preindustriale, Bologna, Il Mulino, pp. 39-63.

Moroni, Marco (2016), “Organizzazione aziendale, indirizzi produttivi e rapporti con il mercato nelle terre della Santa Casa di Loreto", Marca/Marche. Rivista di Storia Regionale, 7, pp. 87-114.

NENCI, Giacomina (1989), “Proprietari e contadini nell'Umbria mezzadrile”, en Covino, Renato et al. (eds.), Storia d'Italia. Le regioni dall'Unità a oggi. L'Umbria, Torino, Einaudi, pp. 189-257.

Ongaro, Giulio; Mocarelli, Luca; Costantini, Fabrizio; Maffi, Luciano (en prensa), Wheat Prices and Wheat Market in the Republic of Venice and in the State of Milan (XVIIIth Century).

Pannacci, Massimo (1994-95), I prezzi dei principali beni di consumo a Gubbio dal 1726 al 1800, Tesi di Laurea, Facoltà di Economia e Commercio, Università degli studi di Perugia.

PAOlini, Aldobrando (1827), "Discorso economico in risoluzione del seguente programma "Con quali industrie potrebbero i possidenti della Maremma ... avvantaggiarne la coltura”, en Continuazione degli atti dell'Accademia economico-agraria dei Georgofili, t. V, Firenze, Galileiana.

Parenti, Giuseppe (1942), Prezzi e mercato de grano a Siena (1546-1765), Firenze, Casa Editrice del Dottore Carlo Cya.

PeCCHIo, Giuseppe (1830), Saggio storico sulla amministrazione finanziaria del ex-Regno d'Italia dal 1802 al 1814, Londra, Stamperia di A. Sincon.

PERSSON, Karl Gunnar (1999), Grain markets in Europe. Integration and deregulation, 1500-1900, Cambridge, Cambridge University Press. https://doi.org/10.1017/ CBO9780511496820

Pescosolido, Guido (2004), Agricoltura e industria nell'Italia unita, Roma-Bari, Laterza.

Pescosolido, Guido (2007), Unità nazionale e sviluppo economico in Italia 1750-1913, Roma-Bari, Laterza.

Polvani, Stefania (1999-2000), I prezzi dei principali prodotti agricoli a Castiglione Fiorentino dal 1767 al 1862, Tesi di Laurea, Facoltà di Economia e Commercio, Università degli Studi di Perugia. 
ReBourg et al., (2002), "Maize introduction in Europe: the history reviewed in the light of molecular data", Theoretical and Applied Genetics, pp. 895-903.

Romano, Ruggiero, coord. (1967), I prezzi in Europa dal XIII secolo a oggi, Torino, Einaudi.

SERENI, Emilio (1997), Storia del paesaggio agrario italiano, Roma-Bari, Laterza.

Storanovic, Traian (1966), "Le mais dans le Balkans”, Annales. Èconomie, Sociétés, Civilisations, 5, pp. 1026-1040.

Strangio, Donatella (2015), "Ripensare la foodcrises: lo Stato Pontificio (1750-1800)", en Vaquero Piñeiro, Manuel et al. (eds.), «Moia la carestia». La scarsità alimentare in età preindustriale, Bologna, Il Mulino, pp. 65-92.

TORRI, Giulia (2017), La vita in villa. Svaghi, lussi e raffinatezze nell'Italia del Settecento, Roma, Donzelli.

VAquero PiñeIro, Manuel et Giommi, Francesca (2017), L'Umbria nelle "memorie" inedite dell'Inchiesta agraria Jacini (1877-1884), Perugia, Editoriale UmbraIstituto per la Storia dell'Umbria Contemporanea.

VIVANTI, Corrado (1967), "I prezzi di alcuni prodotti agricoli a Mantova nella seconda metà del XVIII secolo”, en Romano, Ruggiero (ed.), I prezzi in Europa dal XIII secolo a oggi, Torino, Einaudi, pp. 421-436.

ZANINELLI, Sergio (1964), Una grande aziendaagricola della pianura irrigua lombarda nei secoli XVIII e XIX, Milano, Giuffrè. 